\title{
Applications of Mobile Information System in Rural Area of China
}

\author{
Jiantong Cao and Chunhua Liu \\ ${ }^{1}$ School of Economics and Management, Beijing University of Posts and \\ Telecommunications, Beijing 100876, P.R. China tony000@263.net
}

\begin{abstract}
More and more information system applications have been adopted in China. Telecom operators in China are applying information services and solutions to more and more sectors and areas, of which the rural area is a typical example. Firstly, the paper describes the architecture of the mobile information system, which is based on telecommunication terminals and is realized through text messaging, voice, WAP and other means to satisfy the rural demanding, such as agricultural production, administrative management and other information applications. Secondly, the paper presents the business application model. It is not just the simple use of communication tools and instead, it includes using networks and information resources to the processes of information production, operation, promotion and so on. Thirdly, the paper investigates the value chain and business models. Finally, the benefits for both farmers and telecom operators would be discussed. It can increase the farmers' income, improve the rural market share of Chinese telecom operators and narrow the "information gap" between the cities and rural areas.
\end{abstract}

Keywords: Mobile information system, Rural area, Application

\section{INTRODUCTION}

In near years, telecom operators in China are developing very quickly and have had the biggest users in the world. However, the mobile system application in rural areas is just starting. In this paper, the author pays much attention on the application background, information system, rural demands, industry chain and business model. Then the paper discusses the benefits for both farmers and telecom operators.

In this paper, the author mainly use an empirical study method to research the mobile information system in rural area of China. It quotes some data to show the objective facts, emphasis on the structure of the system and analyzes benefits for both farmers and telecom operators. 


\section{BACKGROUND}

\subsection{Problems in Countryside: Information Asymmetry}

Information asymmetry is one of the main obstacles in rural production and operation. Although China has been advancing informatization many years, the traditional informationization pattern based on PC is not suitable for common farmers. The reasons may be as follows: Firstly, the farmers' culture is low so they are not liable to use PC [1]. Secondly, the economic condition in countryside is not so good that the farmers cannot afford to PCs; Thirdly, the farmers do not reside centrally, so the wire network cannot cover all the rural areas [2].

\subsection{Problems in Countryside are the Key Work of China Government}

From 2004 to 2006, China government put forward three documentations on countryside, in order to increase the farmers income, to improve the production capacity and to construct the new social countryside. In them, China government emphasizes that the whole country should advance information construction in rural areas, fulfill and centralize information resource and construct integrative agriculture information service platform [3].

\subsection{Findings}

In 2005, The MOST (The Ministry of Science and Technology of the People's Republic of China) did a survey about the information acquiring in countryside. Picture 1 shows the results:

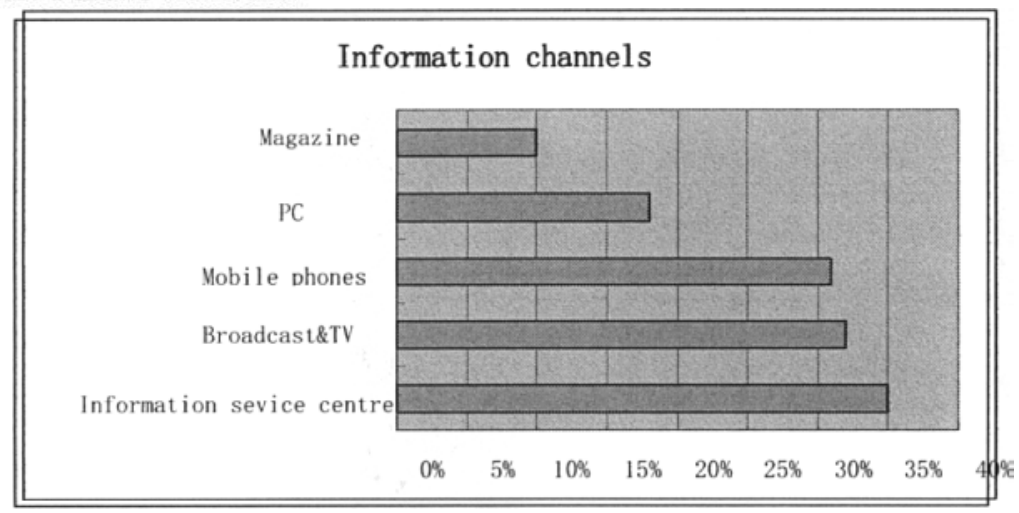

Figure 1. Information Channels in Countryside [4]

We can see from figure 1: The mobile phones are one of the main information acquiring channels for farmers. The channel based on mobile phones is a promising means in rural areas. 


\section{INFORMATION SYSTEM AND RURAL DEMANDS}

\subsection{Information System}

Information system for rural areas is based on mobile phones and is realized through text messaging, voice, WAP and other means to satisfy the rural demanding, such as agricultural production, administrative management and other information applications. [5]

The information system solutions can be describes as figure 2: Firstly the system collects rural information from information centre and information point, such as government, broadcast, magazines, institutions, and so on. Secondly, the information can be transferred to the gateway. Thirdly, the information can be transmitted through many kinds of information terminals in the means of voice, MMS, SMS, and WAP. Finally, the farmers, brokers, enterprises and governments acquire and use the information to create more and more values.

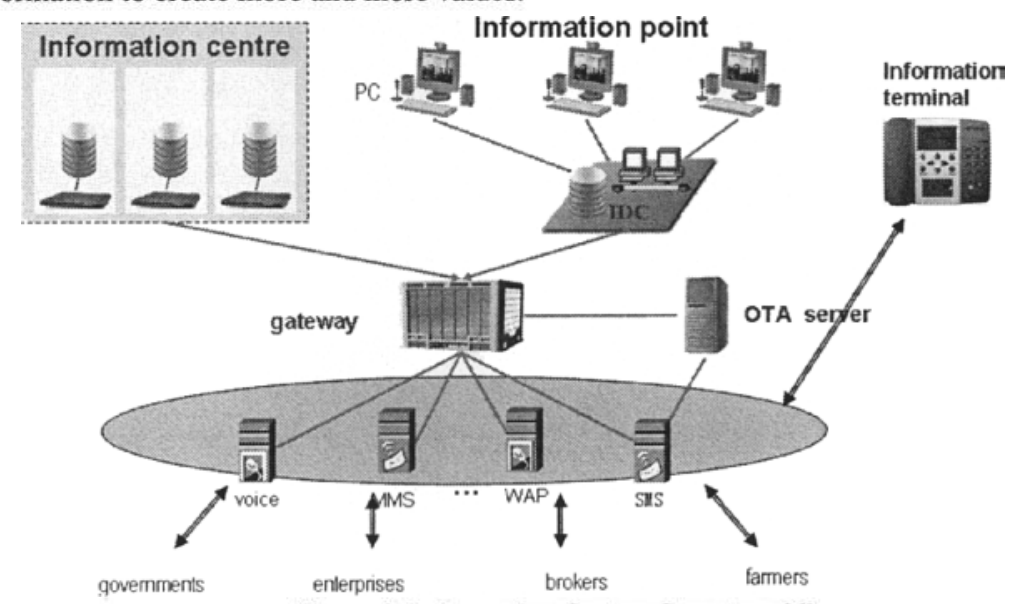

Figure 2. Information System Structure [6]

\subsection{Rural Demands}

The rural demands can be divided into three aspects:

\subsubsection{The Government Needs}

It mainly solves the broadcasting and transmitting problems in the rural government. It concludes the government order issuing, rural instance aviso, labor force information, government affairs transmitting, investment attracting, urgent affairs disposing and so on[4]. This aspect will play a very important role in leading and educating farmers. 


\subsubsection{The Production and Circulating Needs}

It mainly solves the production, supply and marketing problems in rural areas. It concludes planting technology, commodity information, weather report, price market, supply and marketing information and so on [7].This aspect is the most important in the rural information and can create the most added values.

\subsubsection{The Farmers' Livelihood Needs}

It mainly solves the farmers' needs except the production and circulating problems. It concludes education information, medical treatment knowledge, hygiene, culture and entertainment, work force information and so on [7]. This aspect will be very promising with the economic development in rural areas.

\section{INDUSTRY CHAIN AND BUSINESS MODEL}

\subsection{Industry Chain}

Mobile system applied in rural areas can be also described as an industry chain in figure 3: Firstly, the channels collect information from the headstream and form information product. Then the product transmits to information users through the mobile terminals.

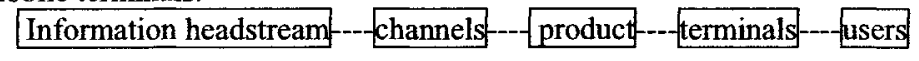

Figure 3. Industry Chain [8]

\subsection{Business Model}

From the above industry chain, we can elicit the scientific business model based on different objects and products.

The first object is the government and enterprises which we can regard as the group customers. Their information needs are clear and urgent. Also they have strong payment capacity. So they are our main income source. We should customize different products according to their different needs.

The second object is the brokers and planting farmers. They have some payment capacity and urgent information needs. We can customize some products according to their different needs and operation subdivision. Then they can pay some fees to the information.

The second object is the common farmers. Their payment capacity is low in some extent and they only have a little knowledge about the information system. So we ought to induct their information needs. For example, at the beginning, the information expenditure can be paid mainly by the government or the enterprises. The common farmers can only pay a few fees or enjoy the free information service. 


\section{BENEFITS FOR BOTH FARMERS SAND TELECOM OPERATORS}

\subsection{Benefits for Farmers}

This information system can strengthen IT (information technology) applied in agriculture and exert mobile technology advantage. So we can utilize it to supply information service for farmers to narrow the "information gap" between the cities and rural areas.

Based on farmers' practical needs, we can establish special organizations to collect and release information. In this way, we can transmit the useful information to remote villages and towns. We can also establish interactive platform to release information about supply and market. So the information channels in rural areas can be solved and the farmers can use information in time to increase their income.

\subsection{Benefits for Telecom Operators [9]}

In advancing mobile system in rural areas, the telecom operators can consolidate and enlarge its market share in rural areas. In addition to that, they can also establish their competition advantage in the long run and exploit the new income source.

\section{CONCLUSION}

This paper mainly researches information system structure, rural demands, industry chain, business model and the benefits for both farmers and telecom operators.

\section{REFERENCES}

1. X. Guo, Y. Hu, and H. Guo, Analysis of Problems in Agriculture Informatization and Brief Discussions on Countermeasures, Management of Agricultural Science and Technology. Volume 26, Number 1, pp.62-4, (2007).

2. F. Deng, Problems and Countermeasures in the Application of Computer Information Technology in Agricultural Sector, Joumal of Library and Information Sciences in Agriculture. Number 2, pp.43-44, (2003).

3. National Development strategy, 2006- 2020, The Central People's Government of the Republic of China (2006).

4. Information Channels in Countryside, The Ministry of Science and Technology of the People's Republic of China (2005).

5. http://www.agri.gov.en(Accessed Apr.20, 2007).

6. National Engineering Research Centre for Information Technology in Agriculture. http://www.nercita.org.cn(Accessed Oct.1, 2006). 
7. Y. Zhang, Agricultural Information needs to the telecommunications industry, High-level forum of telecommunications industry in China (2006).

8. R. Kalakota and M. Robinson, M-Business: The Race to Mobility (McGraw-Hill Companies: Sep. 24, 2001).

9. Q. Gu and C. Yan, Opportunity of mobile operators in rural information, Communication Enterprise Management. Number 2, pp.48-49, (2007). 